\title{
Al and Si Influences on Hydrogen Embrittlement of Carbide-Free Bainitic Steel
}

\author{
Yanguo Li, Cheng Chen, and Fucheng Zhang \\ State Key Laboratory of Metastable Materials Science and Technology, Yanshan University, Qinhuangdao 066004, China \\ Correspondence should be addressed to Fucheng Zhang; zfc@ysu.edu.cn
}

Received 14 September 2013; Accepted 17 October 2013

Academic Editor: Filippo Berto

Copyright (C) 2013 Yanguo Li et al. This is an open access article distributed under the Creative Commons Attribution License, which permits unrestricted use, distribution, and reproduction in any medium, provided the original work is properly cited.

A first-principle method based on the density functional theory was applied to investigate the $\mathrm{Al}$ and Si influences on the hydrogen embrittlement of carbide-free bainitic steel. The hydrogen preference site, binding energy, diffusion behaviour, and electronic structure were calculated. The results showed that hydrogen preferred to be at the tetrahedral site. The binding energy of the cell with Si was the highest and it was decreased to be the worst by adding hydrogen. The diffusion barrier of hydrogen in the cell containing $\mathrm{Al}$ was the highest, so it was difficult for hydrogen to diffuse. Thus, hydrogen embrittlement can be reduced by $\mathrm{Al}$ rather than $\mathrm{Si}$.

\section{Introduction}

Carbide-free bainitic steel (CFBS) is considered to be one of the most promising candidates for heavy-duty railway crossings due to its excellent and compressive properties, such as high strength and toughness. However, some report indicated that brittle spalling and fracture occurred in the CFBS during the service and it was very sensitive to hydrogen embrittlement (HE) [1]. Hydrogen can greatly change the mechanical properties of alloys and steels and therefore can bring about material failure. It has been well proved that the probability of $\mathrm{HE}$ increases with the increase in strength. There was an appropriate silicon concentration (about $2 \mathrm{wt} \%$ ) in CFBS, which suppressed the precipitation of cementite from austenite during the process of bainite transformation [2]. Previous studies proved that aluminium played a similar role to $\mathrm{Si}$, and partial replacement of $\mathrm{Si}$ by $\mathrm{Al}$ had been studied in transformation-induced plasticity (TRIP) steels [3-6]. Besides, experimental results showed that the sensitivity of HE to CFBS was reduced due to the partial replacement of $\mathrm{Si}$ by $\mathrm{Al}$ [7]. However, its exact mechanisms are still only partly understood.

Nowadays, the first-principle study on HE of body-centred cubic $(\mathrm{bcc})$ iron $(\alpha-\mathrm{Fe})$ is well known $[8,9]$. A number of different mechanisms on HE had been proposed including decohesion $[10,11]$, hydrogen-enhanced localised plasticity
$[12,13]$, and high mobility of hydrogen [14]. In the work, the behaviours of interstitial $\mathrm{H}$ atoms inside the pure iron steel and the steel containing aluminium or silicon were investigated using a first-principle approach. The preference site of $\mathrm{H}$ in each cell, the binding energies of $\mathrm{H}$ atom for different interstitial sites, the diffusion barriers of $\mathrm{H}$ between neighbouring sites, and the electronic structure were calculated and discussed. The work provides the micromechanism that the partial replacement of $\mathrm{Si}$ by $\mathrm{Al}$ reduces the HE in CFBS.

\section{Methodology}

The chemical composition of the bainitic steels is shown in Table 1. The steel ingots obtained by vacuum melting are forged into round bars of $\Phi 20 \mathrm{~mm}$. The standard smooth cylindrical tensile samples which have a diameter of $5 \mathrm{~mm}$ and a length of $25 \mathrm{~mm}$ are machined from the bainitic steels. At the same time, the smooth cylindrical specimens for testing hydrogen content are with a diameter of $5 \mathrm{~mm}$ and a length of $50 \mathrm{~mm}$.

In order to determine the hydrogen embrittlement characteristics of the bainitic steels, we have prepared the steels which have a range of different hydrogen contents. The smooth cylindrical tensile specimens are used for cathodic hydrogen charging by the YJ83/2 type DC stabilized power supply. The times of hydrogen charging are $5 \mathrm{~min}, 20 \mathrm{~min}$, 
TABLE 1: Chemical composition of the bainitic steels (wt.\%).

\begin{tabular}{cccccccccc}
\hline & $\mathrm{C}$ & $\mathrm{Si}$ & $\mathrm{Mn}$ & $\mathrm{Cr}$ & $\mathrm{Ni}$ & $\mathrm{Mo}$ & $\mathrm{Al}$ & $\mathrm{P}$ \\
\hline $1 \#$ & 0.30 & 1.80 & 1.76 & 1.71 & 0.39 & 0.35 & 0 & 0.010 & 0.011 \\
$2 \#$ & 0.30 & 1.55 & 1.78 & 1.73 & 0.41 & 0.35 & 0.19 & 0.010 \\
$3 \#$ & 0.30 & 1.02 & 1.83 & 1.75 & 0.40 & 0.34 & 0.75 & 0.010 \\
$4 \#$ & 0.32 & 0.48 & 1.82 & 1.77 & 0.40 & 0.35 & 1.31 & 0.011 \\
\hline
\end{tabular}

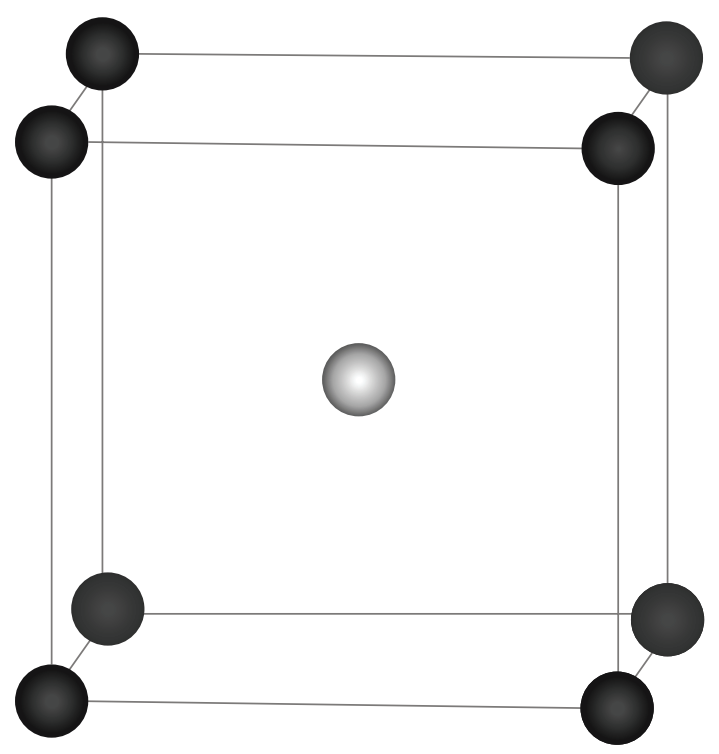

(a)



(b)

Figure 1: Schematic diagram of $\mathrm{FeX}(\mathrm{a})$ and $\mathrm{Fe}_{15} \mathrm{X}$ (b) (Fe black and $\mathrm{X}$ grey, $\mathrm{X}$ represents $\mathrm{Al}$ or $\mathrm{Si}$ ).

$100 \mathrm{~min}$, and $180 \mathrm{~min}$, respectively. The electrolyte is a mixed solution of $0.5 \mathrm{~mol} / \mathrm{L} \mathrm{H}_{2} \mathrm{SO}_{4}+200 \mathrm{mg} / \mathrm{L} \mathrm{Na}_{3} \mathrm{AsO}_{3}$. The current density of hydrogen charging is $10 \mathrm{~mA} / \mathrm{cm}^{2}$. According to the hydrogen charging time, the samples can be obtained with different hydrogen content. The samples can be protected by bright cadmium plating to prevent the hydrogen escaping from the samples. Then the hydrogen of the samples can be uniformly distributed by the homogenization heat treatment at $200^{\circ} \mathrm{C}$ for $10 \mathrm{~h}$. The method of electroplating can be referred to [15]. Moreover, the analysis of the content of hydrogen in the bainitic steels is carried out by a CQY-2 type hydrogen content analyzer.

The hydrogen embrittlement sensitivity to the bainitic steels used in this study is investigated by SSRT. The experimental equipment is the DDL-100 electronic universal testing machine. A slow strain rate, that is, $5.6 \times 10^{-5} \mathrm{~s}^{-1}$ (stretching rate is $0.1 \mathrm{~mm} / \mathrm{min}$ ), is employed in full reflecting the hydrogen embrittlement sensitivity of the bainitic steels.

The calculations presented in this paper were performed using the Cambridge Serial Total-Energy Package (CASTEP), which was based on density-functional theory (DFT), using a plane-wave basis set for the expansion of the electronic wave-function [16]. In the work, the ultrasoft pseudopotential (USPP) [17] was used to describe the computationally expensive core-valence interaction, and the generalised gradient approximation (GGA) of Perdew-Burke-Ernzerhof (PBE)
[18] was employed for the exchange-correlation energy. Brillouin zone sampling was performed using a Monkhorst-Pack grid [19] of special k-points. The electronic occupancies were determined according to a Methfessel-Paxton scheme [20] with an energy smearing of $0.1 \mathrm{eV}$. A plane-wave cutoff energy of $400 \mathrm{eV}$ was used for all calculations. All calculations were employed spin-polarisation to account for the ferromagnetic state of bainitic steel. Unless otherwise stated, the DFT calculations were relaxed respective to supercell shape and volume, as well as all atomic positions, in order to find the minimum energy. During geometry optimisation, convergence criteria were chosen as the energy changes on each atom of less than $5 \times 10^{-6} \mathrm{eV}$ and the force on each atom of less than $0.01 \mathrm{eV} / \AA$.

Two different bcc iron cells were used: $1 \times 1 \times 1$ ( 2 atoms) and $2 \times 2 \times 2$ (16 atoms) conventional bcc cells, corresponding to a k-point sampling of $12 \times 12 \times 12$ and $6 \times 6 \times 6$. One of the iron atoms in each cell was substituted by a $\mathrm{Si}$ or an $\mathrm{Al}$ atom, which was in the minimum energy state as shown in Figure 1.

In the bcc lattice there are two high-symmetry interstitial sites available for the hydrogen atom, that is, the octahedral (O) site and the tetrahedral (T) site. Total energy and lattice distortion of each cell were calculated to estimate the preference site of hydrogen. Binding energy was investigated to characterize the bonding strength of each cell. The diffusion barrier of $\mathrm{H}$ was calculated by a transition state (TS) 
TABLE 2: Calculated results of total energy $\left(E_{\text {total }}\right)$, the energy difference $\left(\Delta E=E_{\mathrm{O}}-E_{\mathrm{T}}\right)$ between $\mathrm{H}$ in the O-site and T-site, and lattice distortion $(a / c)$ in unit cells, eV.

\begin{tabular}{|c|c|c|c|c|c|c|}
\hline & \multicolumn{2}{|c|}{$\mathrm{Fe}_{2} \mathrm{H}$} & \multicolumn{2}{|c|}{$\mathrm{FeSiH}$} & \multicolumn{2}{|c|}{$\mathrm{FeAlH}$} \\
\hline & $\mathrm{T}$ & $\mathrm{O}$ & $\mathrm{T}$ & $\mathrm{O}$ & $\mathrm{T}$ & $\mathrm{O}$ \\
\hline$E_{\text {total }}$ & -1746.321 & -1746.378 & -988.081 & -987.884 & -938.034 & -937.767 \\
\hline$\Delta E$ & \multicolumn{2}{|c|}{-0.057} & \multicolumn{2}{|c|}{0.197} & \multicolumn{2}{|c|}{0.267} \\
\hline$a / c$ & 1.00 & 1.49 & 1.05 & 1.37 & 1.05 & 1.41 \\
\hline
\end{tabular}

TABLE 3: Calculated results of total energy $\left(E_{\text {total }}\right)$, the energy difference $\left(\Delta E=E_{\mathrm{O}}-E_{\mathrm{T}}\right)$ between $\mathrm{H}$ in the O-site and T-site, and lattice distortion $(a / c)$ in supercells, $\mathrm{eV}$.

\begin{tabular}{|c|c|c|c|c|c|c|}
\hline & \multicolumn{2}{|c|}{$\mathrm{Fe}_{16} \mathrm{H}$} & \multicolumn{2}{|c|}{$\mathrm{Fe}_{15} \mathrm{SiH}$} & \multicolumn{2}{|c|}{$\mathrm{Fe}_{15} \mathrm{AlH}$} \\
\hline & $\mathrm{T}$ & $\mathrm{O}$ & $\mathrm{T}$ & $\mathrm{O}$ & $\mathrm{T}$ & $\mathrm{O}$ \\
\hline$E_{\text {total }}$ & -13860.979 & -13860.859 & -13104.230 & -13103.649 & -13052.927 & -13052.410 \\
\hline$\Delta E$ & \multicolumn{2}{|c|}{0.120} & \multicolumn{2}{|c|}{0.581} & \multicolumn{2}{|c|}{0.517} \\
\hline$a / c$ & 1.00 & 1.04 & 1.00 & 1.05 & 0.99 & 1.06 \\
\hline
\end{tabular}

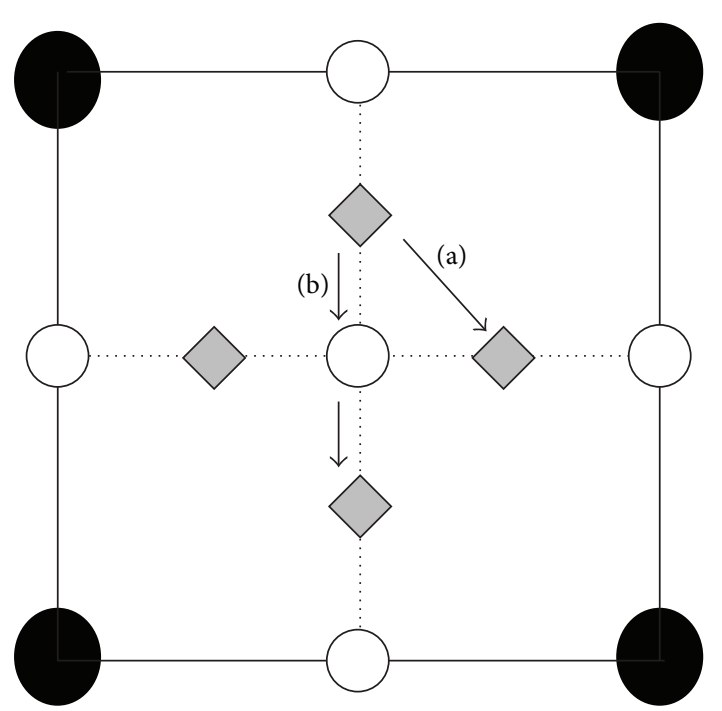

FIgure 2: O-sites and T-sites from a (001) view of the bcc lattice, open circles, and diamonds, respectively. Full circles represent $\mathrm{Fe}$ atoms.

search via the complete linear/quadratic synchronous transit method (LST/QST) [21]. Since hydrogen atom prefers to occupy the tetrahedral sites [22], here the diffusion between two tetrahedral interstitial sites was only considered. There were two possible paths between the adjacent tetrahedral sites: path (a) between the nearest neighbouring tetrahedral sites (T-T) and path (b) between the tetrahedral sites via the $\mathrm{O}$-site in the middle of the path (T-O-T), as shown in Figure 2. The electron density and the state density were computed at their equilibrium lattice constants and optimise structures.

\section{Results and Discussion}

The HE characteristics of CFBS with different sets of aluminium content ( $0 \mathrm{wt} \%, 0.19 \mathrm{wt} \%, 0.75 \mathrm{wt} \%$, and $1.31 \mathrm{wt} \%)$ have been investigated, as shown in Figure 3.

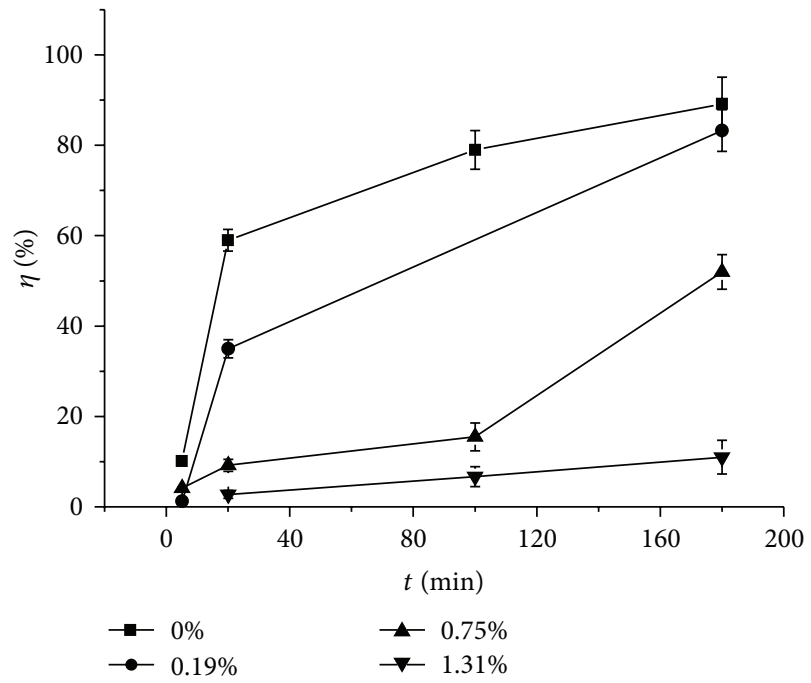

FIGURE 3: Relationships between the embrittlement index and hydrogen charging time of the four different aluminium contents of bainitic steels at a strain rate of $5.6 \times 10^{-5} \mathrm{~s}^{-1}$.

The total content of aluminium and silicon is about $1.8 \mathrm{wt} \%$, so the content of silicon is $1.8 \mathrm{wt} \%, 1.55 \mathrm{wt} \%$, $1.02 \mathrm{wt} \%$, and $0.48 \mathrm{wt} \%$, respectively. It can be seen that the embrittlement index increases as hydrogen content increases; however, it decreases as aluminium content increase. We consider that aluminium can refine bainite, tendency to increase $M_{s}$ and $M_{f}$, which is found to be the most sensitive to hydrogen by a metallographic microscope and an X-ray diffraction analysis. In this work, the influences of $\mathrm{Al}$ and $\mathrm{Si}$ on $\mathrm{HE}$ were further studied using first-principle.

3.1. Hydrogen Site Preference in Each Cell. In the bcc lattice, two high-symmetry sites ( $\mathrm{O}$ and $\mathrm{T}$ ) competed to locate the interstitial atoms as mentioned earlier. Both sites were investigated for $\mathrm{H}$ atoms in order to find the optimal site. The calculation results of unit cells and supercells are summarised in Tables 2 and 3. 
TABLE 4: Calculated binding energy of unit cells, eV.

\begin{tabular}{|c|c|c|c|c|c|c|c|c|c|}
\hline & \multirow{2}{*}{$\mathrm{Fe}_{2}$} & \multicolumn{2}{|c|}{$\mathrm{Fe}_{2} \mathrm{H}$} & \multirow{2}{*}{$\mathrm{FeSi}$} & \multicolumn{2}{|c|}{$\mathrm{FeSiH}$} & \multirow{2}{*}{$\mathrm{FeAl}$} & \multicolumn{2}{|c|}{$\mathrm{FeAlH}$} \\
\hline & & $\mathrm{T}$ & $\mathrm{O}$ & & $\mathrm{T}$ & $\mathrm{O}$ & & $\mathrm{T}$ & $\mathrm{O}$ \\
\hline$E_{b}(\mathrm{eV})$ & 5.44 & 4.693 & 4.712 & 6.06 & 4.604 & 4.538 & 4.95 & 4.312 & 4.223 \\
\hline$\Delta \%^{\mathrm{a}}$ & - & $13.75 \%$ & $13.40 \%$ & - & $24.01 \%$ & $25.09 \%$ & - & $12.83 \%$ & $14.63 \%$ \\
\hline
\end{tabular}

${ }^{\mathrm{a}} \Delta \%=\left[E\left(\mathrm{Fe}_{n} \mathrm{XH}\right)-E\left(\mathrm{Fe}_{n} \mathrm{X}\right)\right] / E\left(\mathrm{Fe}_{n} \mathrm{X}\right) \times 100 \%$.

TABLE 5: Calculated binding energy of supercells, eV.

\begin{tabular}{|c|c|c|c|c|c|c|c|c|c|}
\hline & \multirow{2}{*}{$\mathrm{Fe}_{16}$} & \multicolumn{2}{|c|}{$\mathrm{Fe}_{16} \mathrm{H}$} & \multirow{2}{*}{$\mathrm{Fe}_{15} \mathrm{Si}$} & \multicolumn{2}{|c|}{$\mathrm{Fe}_{15} \mathrm{SiH}$} & \multirow{2}{*}{$\mathrm{Fe}_{15} \mathrm{Al}$} & \multicolumn{2}{|c|}{$\mathrm{Fe}_{15} \mathrm{AlH}$} \\
\hline & & $\mathrm{T}$ & $\mathrm{O}$ & & $\mathrm{T}$ & $\mathrm{O}$ & & $\mathrm{T}$ & $\mathrm{O}$ \\
\hline$E_{b}(\mathrm{eV})$ & 5.44 & 5.314 & 5.307 & 5.52 & 5.386 & 5.352 & 5.38 & 5.262 & 5.230 \\
\hline$\Delta \%$ & - & $2.38 \%$ & $2.51 \%$ & - & $2.52 \%$ & $3.14 \%$ & - & $2.28 \%$ & $2.87 \%$ \\
\hline
\end{tabular}

Even if on average the density of hydrogen absorbed in iron is expected to be small, it can be accumulated locally in some regions where the density is high. It is at the Osite that the total energy is the lowest for high concentrations $\left(\mathrm{Fe}_{2} \mathrm{H}\right)$. Generally speaking, the lowest energy corresponds to the most stable site. However, it induces a large deformation $(a / c=1.49)$ on the bcc lattice where $\mathrm{H}$ is at the $\mathrm{O}$-site. There is no distortion of lattice for $\mathrm{H}$ at the T-site and the total energy is slightly higher $(0.056 \mathrm{eV})$. For FeSiH and FeAlH cells, $\mathrm{H}$ at the T-site corresponds to the lowest energy and the least distortion. Table 2 shows that it induces a slight deformation where $\mathrm{H}$ is at both the $\mathrm{T}$-site and $\mathrm{O}$-site in supercells. However, $\mathrm{H}$ prefers a T-site over an $\mathrm{O}$-site by $0.581 \mathrm{eV}$ and $0.517 \mathrm{eV}$ for $\mathrm{Fe}_{15} \mathrm{SiH}$ and $\mathrm{Fe}_{15} \mathrm{AlH}$. Therefore, we are more inclined towards hydrogen at $\mathrm{T}$-sites than at $\mathrm{O}$-site.

3.2. Binding Energy. The binding energy of the crystal can be used to characterize the bonding strength of crystal, which can be expressed as follows:

$$
E_{b}=\frac{1}{(n+2)\left[n \times E(\mathrm{Fe})+E(\mathrm{X})+E(\mathrm{H})-E\left(\mathrm{Fe}_{n} \mathrm{XH}\right)\right]},
$$

where $E(\mathrm{Fe}), E(\mathrm{X})$, and $E(\mathrm{H})$ are the energy of the isolated $\mathrm{Fe}$, $\mathrm{X}(\mathrm{Si}$ or $\mathrm{Al})$, and $\mathrm{H}$ atom, respectively. $E\left(\mathrm{Fe}_{n} \mathrm{XH}\right)$ is the total energy of $\mathrm{Fe}_{n} \mathrm{XH}$ cell, which has been optimized, and $n$ is the number of atoms. The higher the binding energy is, the higher the strength is. All results of binding energy are listed in the Tables 4 and 5. The binding energy of the cell with hydrogen is less than that without hydrogen. It indicates that the introduction of hydrogen reduces the binding energy. Besides, the degree of reduction increases with the increase of hydrogen content. The decohesion theory indicates that, when the hydrogen electron enters the unfillable $3 \mathrm{~d}$ electronic shell in the pure iron cell, the repulsive force increases; however, the binding energy decreases.

For the cells containing silicon or aluminium, the binding energy increases when an iron atom is the substituted by a silicon atom. However, the degree of reduction is the highest when a hydrogen atom is added, which corresponds to the macroscopic phenomenon that the higher it strength is, the more sensitive to $\mathrm{HE}$ is. The binding energy decreases a little
TABLE 6: Diffusion barrier of hydrogen in pure iron, eV.

\begin{tabular}{lcc}
\hline & $\mathrm{Fe}_{2} \mathrm{H}$ & $\mathrm{Fe}_{16} \mathrm{H}$ \\
\hline T-T & 0.159 & 0.111 \\
T-O-T & 0.448 & 0.179 \\
\hline
\end{tabular}

TABLE 7: Diffusion barrier of hydrogen in the system with silicon or aluminium, $\mathrm{eV}$.

\begin{tabular}{ccccc}
\hline & $\mathrm{FeSiH}$ & $\mathrm{FeAlH}$ & $\mathrm{Fe}_{15} \mathrm{SiH}$ & $\mathrm{Fe}_{15} \mathrm{AlH}$ \\
\hline $\mathrm{T}-\mathrm{T}$ & 0.404 & 0.514 & 0.056 & 0.117 \\
\hline
\end{tabular}

when an iron atom is substituted by an aluminium atom, and the degree of reduction is the lowest when a hydrogen atom is added. It can be concluded that the aluminium replacing silicon can reduce the HE of CFBS.

3.3. Diffusion Behaviour of Hydrogen. Hydrogen as a temporary alloying element in steel has high diffusivity and mobility, which is a major reason for $\mathrm{HE}$. The diffusion barriers of hydrogen along the two paths in pure $\alpha$-Fe cell are calculated and compared with experimental values. The calculated values are reported in $[14,23,24]$, which are also listed in the Table 6.

In the first direction of the T-T path, the calculated energy barriers of $\mathrm{Fe}_{2} \mathrm{H}$ and $\mathrm{Fe}_{16} \mathrm{H}$ are $0.159 \mathrm{eV}$ and $0.111 \mathrm{eV}$. The former result is slightly larger than the experimental value, but the latter one is in good agreement with the experimental value is $0.035 \sim 0.142$ [23], and the calculated values are 0.088 , $0.106[14,24]$ However, the results of the second T-O-T path are much higher than the experimental value. In other words, the hydrogen atom prefers energetically to diffuse between the nearest neighbouring sites. Thus the energy barriers of systems containing a silicon or are aluminium atom are calculated according to the path (a), which are listed in Table 7.

It can be clearly seen that the energy barriers of hydrogen in the Fe-Al system are much higher than those in the FeSi system. In supercells especially, the calculated value of $0.117 \mathrm{eV}$ of $\mathrm{Fe}_{15} \mathrm{AlH}$ is double that of $0.056 \mathrm{eV}$ of $\mathrm{Fe}_{15} \mathrm{SiH}$. It indicates that hydrogen diffuses more difficultly if silicon is substituted by aluminium. It further proves that $\mathrm{HE}$ can be reduced by the partial replacement of $\mathrm{Si}$ by $\mathrm{Al}$. 


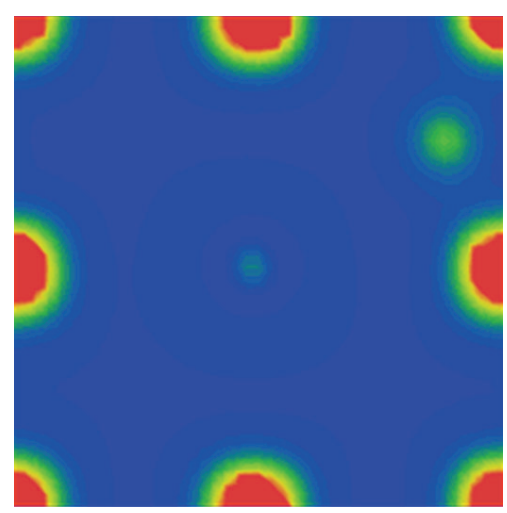

(a)

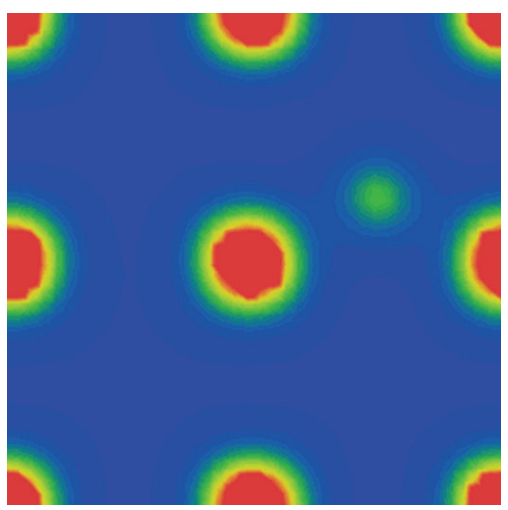

(c)

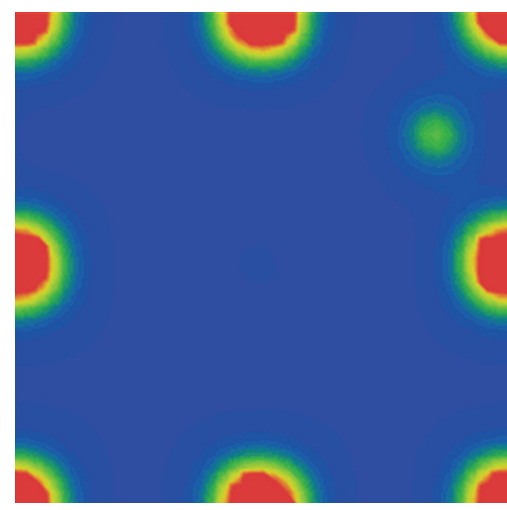

(b)

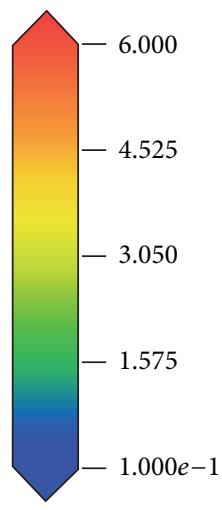

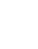

FIGURE 4: Electron density distribution map of supercells on the (200) plane. (a) $\mathrm{Fe}_{16} \mathrm{H}$, (b) $\mathrm{Fe}_{15} \mathrm{SiH}$, and (c) $\mathrm{Fe}_{15} \mathrm{AlH}$.

\subsection{Electronic Structure. Valence charge density distribution} reveals the features of the atomic bonds [25]. Figure 4 illustrates the charge density distribution map of a $\mathrm{Fe}_{15} \mathrm{XH}$ ( $\mathrm{X}$ for $\mathrm{Fe}, \mathrm{Si}$, or $\mathrm{Al}$ ) supercell on the (200) plane.

It can be seen that the valence charge is mainly concentrated around the Fe atoms; the charge density around the $\mathrm{Si}$ atom is smaller and that around the $\mathrm{Al}$ atom is the lowest. It can be considered that there are more valence electrons for the $\mathrm{Fe}$ atom and less for $\mathrm{Si}$ or $\mathrm{Al}$ atoms. Besides, both $\mathrm{Si}$ and $\mathrm{Al}$ atoms have clear repulsion to hydrogen, which can also be seen in Figure 4. There is no significant difference between $\mathrm{Fe}_{15} \mathrm{SiH}$ and $\mathrm{Fe}_{15} \mathrm{AlH}$ in charge density distribution. However, it is very different in the density of states, as shown in Figure 5.

Figure 5(a) shows the calculated total density of states (TDOS) and partial density of states (PDOS) of the Fe-Si system. One can see that the TDOS at the Fermi level $\left(E_{F}\right)$ is not zero, and band gap does not occur in the vicinity of $E_{F}$, which corresponds to be metallic. There are three peaks in the valence band: one at about $-10 \mathrm{eV}$ that is mainly contributed by the s states of the $\mathrm{Si}$ atom. The other two peaks from -8 to $0 \mathrm{eV}$ are dominated by the $\mathrm{d}$ states of the Fe atom. There is a band gap in which DOS is zero from -9 to $-8 \mathrm{eV}$. The TDOS in $E_{F}$ is not zero and still reflects a metallic character after the addition of a hydrogen atom, as shown in Figure 5(b). However, a new peak appears from -9 to $-8 \mathrm{eV}$, which is mainly caused by hybridisation between $\mathrm{s}$ states of $\mathrm{H}$ and $\mathrm{p}$ states of Si. The band gap from -9 to $-8 \mathrm{eV}$ in the Fe-Si system has a right offset and the width is decreased when hydrogen is added. The TDOS of the Fe-Al system (Figure 5(c)) in $E_{F}$ is not zero, either. There is no band gap in the valance band. However, one appears at about $-8 \mathrm{eV}$ after the addition of hydrogen (Figure 5(d)). It can be considered that the electron densities of $\mathrm{Al}$ and $\mathrm{Fe}$ atoms are redistributed by hydrogen. In addition, it is at $-9 \mathrm{eV}$ that the density of states is the highest for hydrogen atoms in the $\mathrm{Fe}-\mathrm{Al}-\mathrm{H}$ system, which is different from the Fe-Si-H system. There is a new peak from -10 to $-8 \mathrm{eV}$, which is also because hydrogen has an effect on the interaction between $\mathrm{Al}$ and $\mathrm{Fe}$ atoms and thus makes a new peak occur from -10 to $-8 \mathrm{eV}$.

\section{Conclusions}

(1) In pure $\alpha$-Fe, hydrogen in the octahedral site is more stable for high concentrations $\left(\mathrm{Fe}_{2} \mathrm{H}\right)$, but it induces a large deformation on the bcc lattice. Hydrogen prefers tetrahedral sites for low concentrations. In cells with $\mathrm{Si}$ or $\mathrm{Al}$, hydrogen is eager to enter tetrahedral sites.

(2) The binding energy of the cell with $\mathrm{Si}$ is the highest, and it is severely reduced by the addition of hydrogen, which demonstrates that HE increases with the increase strength; HE can be reduced by the partial replacement of Si by Al. 


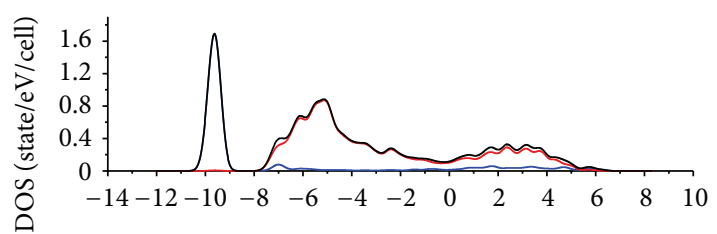

- Si-s

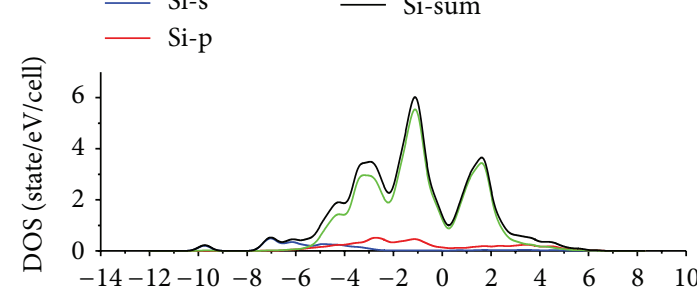

- Fe-s

— Fe-p



— Sum
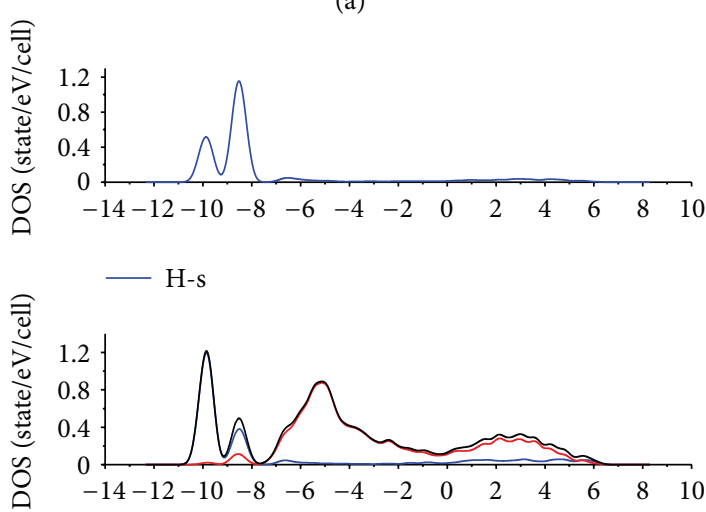

$-\mathrm{Si}-\mathrm{s}$



- Si-p

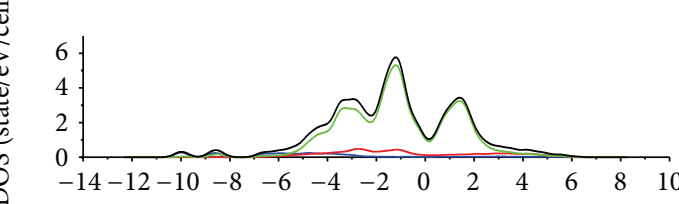

- Fe-s

离

- Fe-p

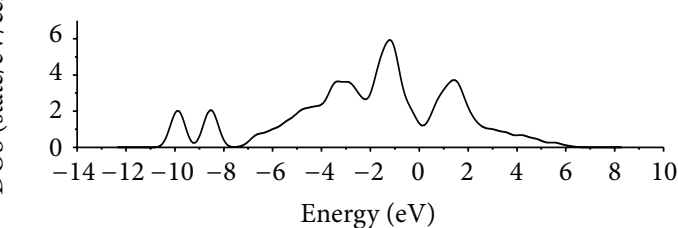

— Sum

(b)
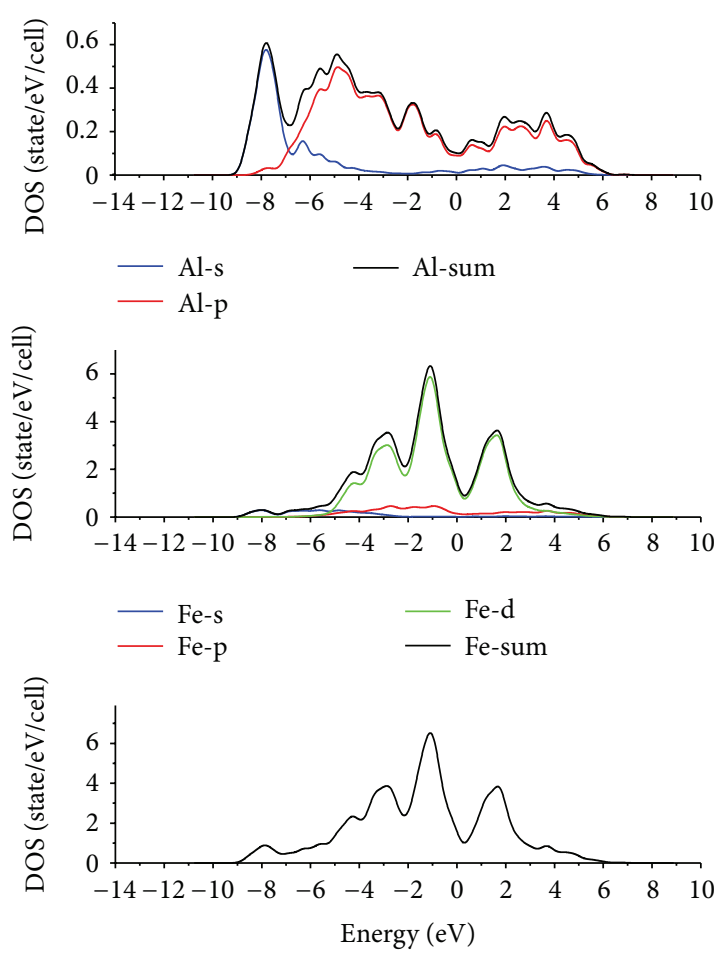

_ Sum

(c)
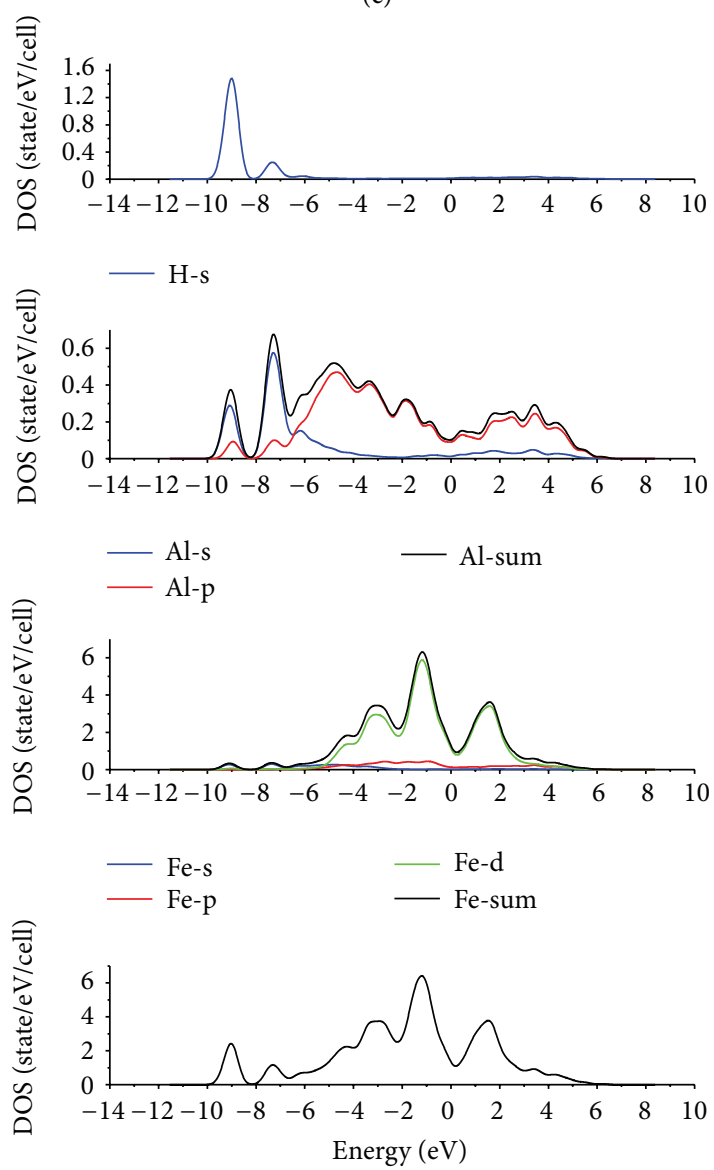

(d)

Figure 5: Partial and total density of states. (a) Fe-Si system, (b) Fe-Si-H system, (c) Fe-Al system, and (d) Fe-Al-H system. 
(3) Hydrogen atoms energetically prefer to diffuse between the nearest neighbouring sites. The diffusion barrier of hydrogen in the cell containing $\mathrm{Al}$ is the highest and it is difficult for hydrogen to diffuse, which is another reason that $\mathrm{HE}$ can be reduced by the replacement of Si by Al.

\section{Acknowledgments}

The paper Sponsored by National Science Foundation for Distinguished Young Scholars (no. 50925522) and the National Natural Science Foundation of China (no. 50871094).

\section{References}

[1] F. C. Zhang, C. L. Zheng, B. Lv, T. S. Wang, M. Li, and M. Zhang, "Effects of hydrogen on the properties of bainitic steel crossing," Engineering Failure Analysis, vol. 16, no. 5, pp. 1461-1467, 2009.

[2] F. G. Caballero, H. K. D. H. Bhadeshia, K. J. A. Mawella, D. G. Jones, and P. Brown, "Very strong low temperature bainite," Materials Science and Technology, vol. 18, no. 3, pp. 279-284, 2002.

[3] C. Garcia-Mateo, F. G. Caballero, and H. K. D. H. Bhadeshia, "Acceleration of low-temperature bainite," ISIJ International, vol. 43, no. 11, pp. 1821-1825, 2003.

[4] T. Hojo, K. Sugimoto, Y. Mukai, and S. Ikeda, "Effects of aluminum on delayed fracture properties of ultra high strength low alloy TRIP-aided steels," ISIJ International, vol. 48, no. 6, pp. 824-829, 2008.

[5] E. Jimenez-Melero, N. H. van Dijk, L. Zhao et al., "Characterization of individual retained austenite grains and their stability in low-alloyed TRIP steels," Acta Materialia, vol. 55, no. 20, pp. 6713-6723, 2007.

[6] M. Gomez, C. I. Garcia, D. M. Haezebrouck, and A. J. Deardo, "Design of composition in (Al/Si)-alloyed TRIP steels," ISIJ International, vol. 49, no. 2, pp. 302-311, 2009.

[7] C. L. Zheng, B. Lv, C. Chen, Z. Yan, F. Zhang, and L. Qian, "Hydrogen embrittlement of a manganese-aluminum highstrength bainitic steel for railway crossings," ISIJ International, vol. 51, no. 10, pp. 1749-1753, 2011.

[8] R. Matsumoto, Y. Inoue, S. Taketomi, and N. Miyazaki, "Influence of shear strain on the hydrogen trapped in bcc-Fe: a firstprinciples-based study," Scripta Materialia, vol. 60, no. 7, pp. 555-558, 2009.

[9] D. Psiachos, T. Hammerschmidt, and R. Drautz, "Ab initio study of the interaction of $\mathrm{H}$ with substitutional solute atoms in $\alpha$ Fe: trends across the transition-metal series," Computational Materials Science, vol. 65, pp. 235-238, 2012.

[10] A. R. Troiano, "The role of hydrogen and other interstitials in the mechanical behaviour of metals," Transactions of ASM, vol. 52, pp. 54-80, 1960.

[11] R. A. Oriani and P. H. Josephic, "Equilibrium aspects of hydrogen-induced cracking of steels," Acta Metallurgica, vol. 22, no. 9, pp. 1065-1074, 1974.

[12] C. D. Beachem, "A new model for hydrogen-assisted cracking (hydrogen "embrittlement")," Metallurgical Transactions, vol. 3, no. 2, pp. 441-455, 1972.

[13] H. K. Birnbaum and P. Sofronis, "Hydrogen-enhanced localized plasticity-a mechanism for hydrogen-related fracture," Materials Science and Engineering A, vol. 176, no. 1-2, pp. 191-202, 1994.
[14] D. E. Jiang and E. A. Carter, "Diffusion of interstitial hydrogen into and through bcc Fe from first principles," Physical Review B, vol. 70, no. 6, Article ID 064102, 9 pages, 2004.

[15] C. L. Zheng, B. Lv, F. C. Zhang, Z. G. Yan, R. Dan, and L. H. Qian, "Effect of secondary cracks on hydrogen embrittlement of bainitic steels," Materials Science and Engineering A, vol. 547, pp. 99-103, 2012.

[16] M. D. Segall, P. J. D. Lindan, M. J. Probert et al., "First-principles simulation: ideas, illustrations and the CASTEP code," Journal of Physics Condensed Matter, vol. 14, no. 11, pp. 2717-2744, 2002.

[17] D. Vanderbilt, "Soft self-consistent pseudopotentials in a generalized eigenvalue formalism," Physical Review B, vol. 41, no. 11, pp. 7892-7895, 1990.

[18] J. P. Perdew, K. Burke, and M. Ernzerhof, "Generalized gradient approximation made simple," Physical Review Letters, vol. 77, no. 18, pp. 3865-3868, 1996.

[19] H. J. Monkhorst and J. D. Pack, "Special points for Brillouinzone integrations," Physical Review B, vol. 13, no. 12, pp. 5188$5192,1976$.

[20] M. Methfessel and A. T. Paxton, "High-precision sampling for Brillouin-zone integration in metals," Physical Review B, vol. 40, no. 6, pp. 3616-3621, 1989.

[21] T. A. Halgren and W. N. Lipscomb, “The synchronous-transit method for determining reaction pathways and locating molecular transition states," Chemical Physics Letters, vol. 49, no. 2, pp. 225-232, 1977.

[22] P. Khowash, S. Gowtham, and R. Pandey, "Electronic structure calculations of substitutional and interstitial hydrogen in $\mathrm{Nb}$," Solid State Communications, vol. 152, no. 9, pp. 788-790, 2012.

[23] Y. Hayashi and W. M. Shu, "Iron (ruthenium and osmium)hydrogen systems," Solid State Phenomena, vol. 73-75, pp. 65$114,2000$.

[24] D. C. Sorescu, "First principles calculations of the adsorption and diffusion of hydrogen on Fe(1 000$)$ surface and in the bulk," Catalysis Today, vol. 105, no. 1, pp. 44-65, 2005.

[25] G. H. Lu, S. H. Deng, and T. M. Wang, "Theoretical tensile strength of an Al grain boundary," Physical Review B, vol. 69, no. 13, Article ID 134106, 9 pages, 2004. 

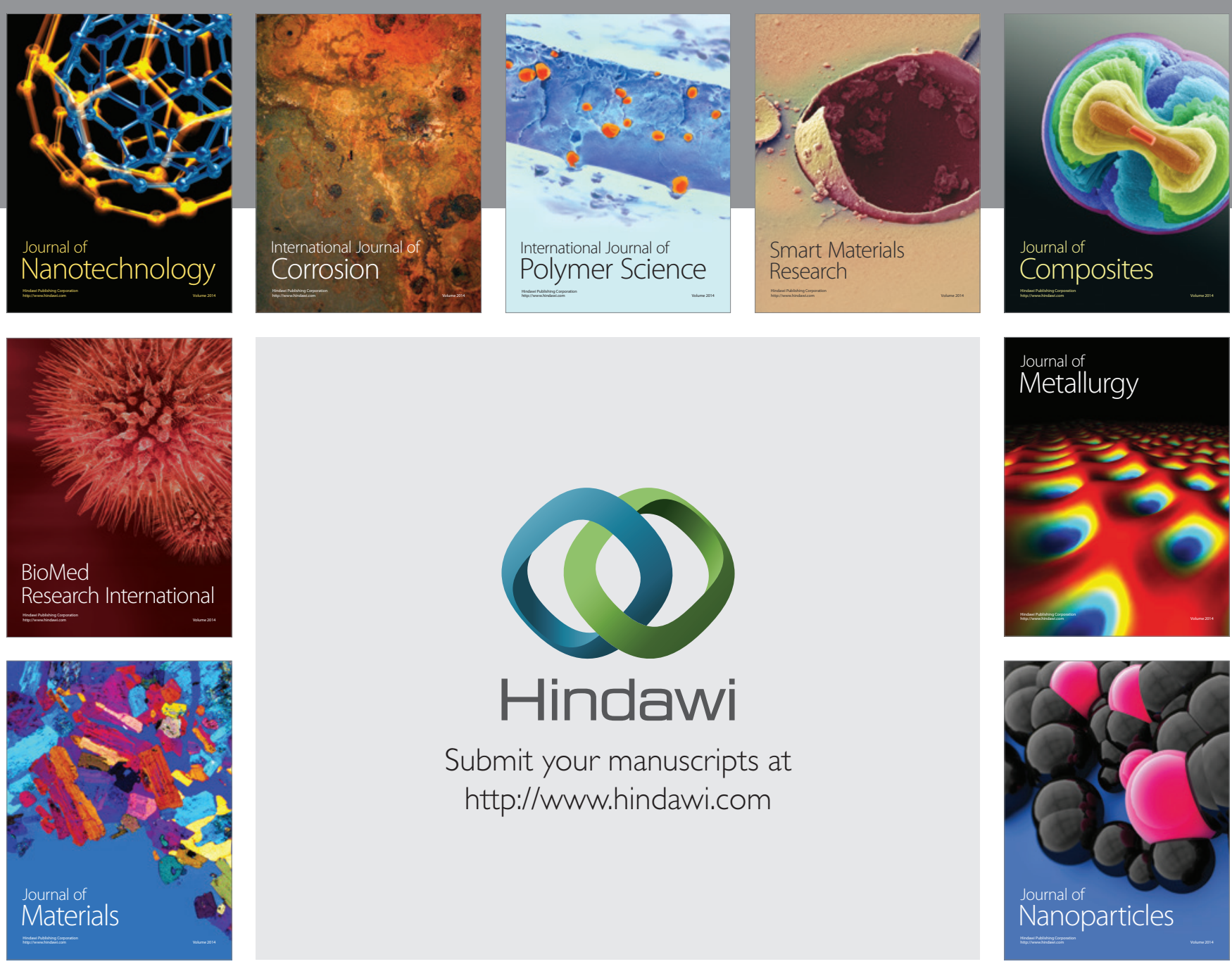

Submit your manuscripts at http://www.hindawi.com
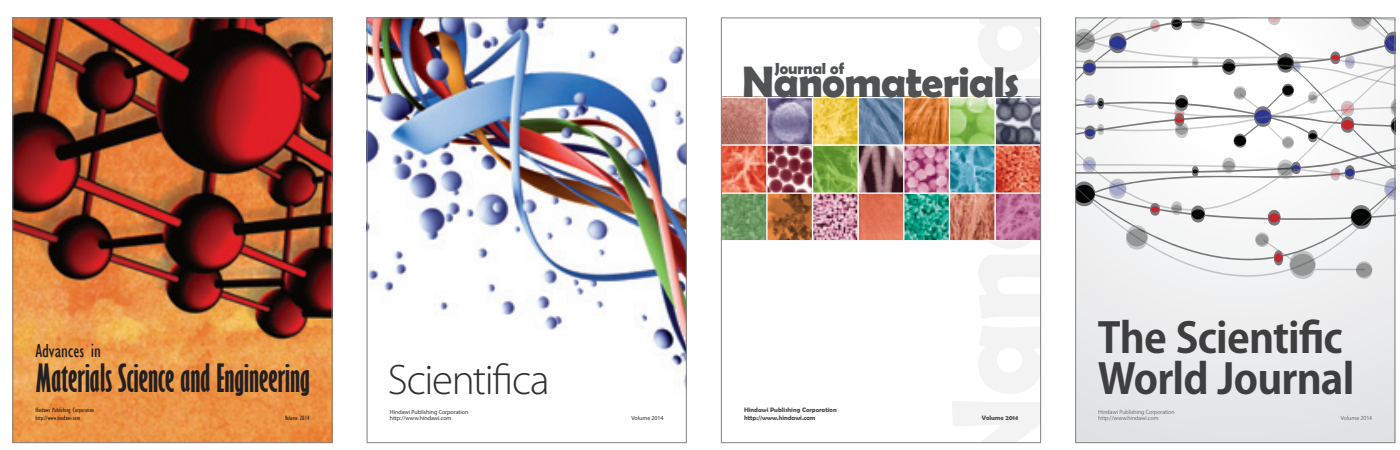

\section{The Scientific World Journal}
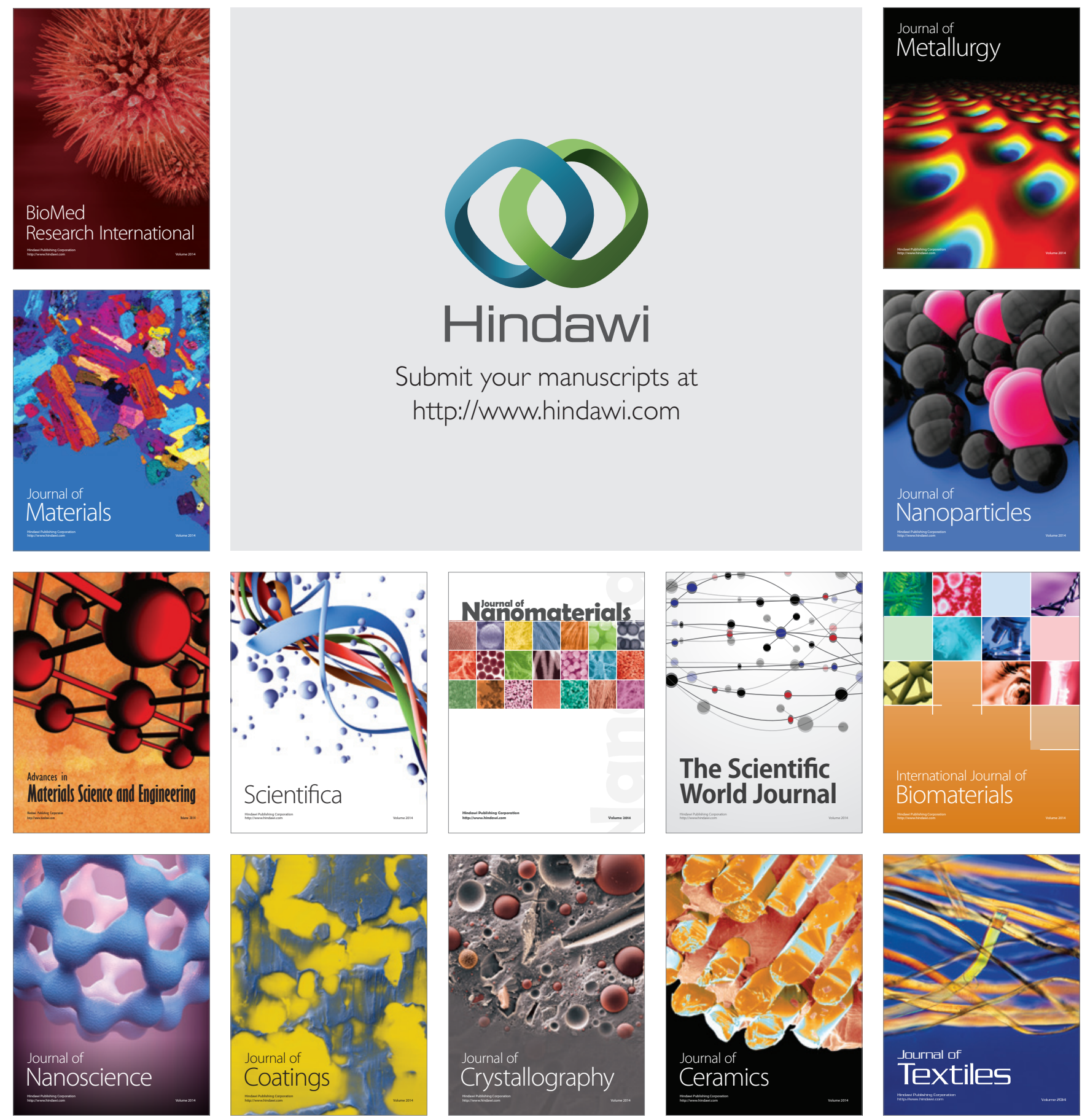